\title{
Implications of Big Box Retail Location on Regional Profits, Consumer Utility, and Land Rents
}

\author{
Mark Stater and Michael S. Visser ${ }^{*}$
}

\begin{abstract}
This paper uses a monocentric city model to examine the effects of big box retailing on local retail prices, land values and utility. Relative to small local retailers, the big box offers a price discount that increases in its marginal cost advantage. Big box entry reduces local retail prices and profits, but provides an increase in household utility that depends positively on the distance between the big box location and the CBD. However, big box locations are unstable with imperfectly competitive land markets, as developers and local governments have incentives to entice big boxes to switch locations.
\end{abstract}

Key Words: big box retail, location analysis, cost advantage, regional land and output markets, welfare analysis

JEL Classifications: R11, R13, R14, R32

\section{INTRODUCTION}

The phenomenon of big box retailing is widely regarded as having its roots in the founding of Wal-Mart by Arkansas businessman Sam Walton in 1962. The company has grown rapidly through its ability to price at significant discounts relative to other retailers. This has been credited to production efficiencies in the procurement, transport, and management of inventories (Welles, 1993). Wal-Mart's annual sales stood at more than \$300 billion in 2005, and in the same year was the largest private employer in the United States with 1.3 million employees (The Economist, 2006).

Concerns about the effects of Wal-Mart and other retail giants on local economies have been raised in jurisdictions throughout the U.S. (DeFao, 2003). Opponents of big box retailers contend that although they offer consumers lower prices, they also harm local retailers, displace workers and depress wages. Additional concerns center on disamenities such as increased traffic congestion, noise pollution, and loss of neighborhood character (Lohr, 2003; Dejka, 2004). Local governments have responded to the concerns of citizens and activist groups by enacting restrictions on the locations and/or sizes of large retail developments (Garrison and Lin, 2004; Sanchez, 2004). Rhee (2004) shows that voter preferences determine land use patterns, so elected city managers are likely to consider household utility outcomes when making zoning decisions.

The economics literature on the effects of big box retail consists primarily of empirical studies that find negative effects on retail prices (Basker, 2005a), household expenditures (Hausman and Leibtag, 2005; Irwin and Clark, 2006), and local retail earnings (Dube, Lester, and Eidlin, 2005; Neumark, Zhang, and Ciccarella, 2005; Artz and Stone, 2006). Some studies

\footnotetext{
${ }^{*}$ Stater is affiliated with the Department of Economics, Trinity College, Hartford, CT. Visser is affiliated with the Department of Economics, Sonoma State University, Rohnert Park, CA.

Contact author: Michael Visser, 1801 E. Cotati Ave., Rohnert Park, CA 94928. Telephone: (707) 664-3297. Fax: (707) 664-4009. E-mail: visser@sonoma.edu.

(C) Southern Regional Science Association 2010.

ISSN 1553-0892

SRSA, 1601 University Avenue, PO Box 6025, Morgantown, West Virginia 26506-6025, USA.
} 
find positive effects on local retail employment (Hicks and Wilburn, 2001; Basker, 2005b), while one study finds negative effects (Neumark, Zhang, and Ciccarella, 2005).

Empirical research may face an inherently difficult challenge in explaining how the related social and political debates unfold because this requires a comprehensive assessment of how urban economic variables impacted by big box retail (e.g., goods prices, land prices, wages, and commuting costs) interact to determine the welfare of local residents. Theoretical models, in contrast, are potentially well suited to analysis of welfare issues. Using a standard urban model, one can derive a parametric expression for equilibrium utility and then perform comparative static analysis to examine how changes in parameters affect the welfare of local residents. In light of Rhee's finding on voter preferences (2004), the ability to examine welfare impacts on households is important.

The theoretical urban literature has focused primarily on the factors responsible for the emergence of large retailers. Munroe (2001) highlights the importance of changes in the cost structures of retail firms, while Wassmer (2003) considers the role of the fiscal and growth control policies of local governments. More generally, urban theory has identified important forces contributing to the endogenous development of secondary business and shopping centers, such as increasing returns in production; imperfect competition; communications externalities; scale economies in shopping; transportation and marketplace setup costs; zoning; and voting behavior (Fujita and Ogawa, 1982; d'Aspremont, Gabszewicz, and Thisse, 1983; Ota and Fujita, 1993; de Palma, Liu, and Thisse, 1994; Anas and Kim, 1996; Berliant and Konishi, 2000; Rhee, 2004).

The concept of a secondary employment center (SEC) is also clearly relevant to big box retail developments. Cavailhes, Gaigne, and Thisse (2004) show that the number of SECs in a city is positively related to urban population and commuting costs - predictions supported by the work of McMillen and Smith (2003). Smith and Zenou (1997) show that demand shocks in primary centers, together with a system of unemployment insurance taxes, can give rise to SECs. Henderson and Mitra (1996) portray the development of SECs as the tradeoff between greater efficiency of information exchange and higher rents or commuting costs and wages as firms move closer to the core of the city. Fujita and Thisse (2002) develop a model where the relatively high land consumption of final-goods producing firms causes them to move away from the central business district (CBD) and establish SECs.

Fujita, Thisse, and Zenou (1997) model the endogenous formation of a secondary employment center. A firm that is large relative to the local labor market chooses its optimal location in the city, given that there is a competitive cluster of firms in the CBD. If communications requirements with $\mathrm{CBD}$ firms are low or travel costs are high, then the firm locates away from the city center, creating an SEC. The firm has monopsony power over its workers and is able to pay them lower wages because of lower commuting costs.

Our paper complements prior research by considering how an efficiency advantage in the output market affects prices, land values, and the welfare of local economic agents in the absence of commuting costs. Specifically, we augment a standard theoretical model of a closed monocentric linear city with a big box retail firm that is larger and has lower production costs than existing local retailers. Even if the big box retailer does not have to compensate shoppers for additional commuting costs, we find that it charges a lower price than the CBD (or "downtown") retailers. Under certain circumstances, the big box price discount can be related in 
precise terms to its marginal cost advantage. In contrast to subcenter models that assume a small city and thus a fixed household utility level, we examine the welfare impact of the entry of the big box retailer on household utility.

The entry of the big box retailer into the local economy generally reduces the profits of downtown businesses and increases the utility of local residents because of the increased competition in the output market. Land values are also affected by big box entry. Land values decrease around the CBD and increase around the big box development (despite there being no commuting costs in the model). Given big box entry into the economy, equilibrium household utility and equilibrium downtown retail profits are both increasing in the distance between the big box and the CBD. Since downtown retailers are indifferent to the exact big box location, the interests of all local economic agents are served by a big box location that is at least some minimal distance away from downtown. Nonetheless, our analysis also helps explain the apparent instability of big box locations on the basis of the incentives that land developers and local governments have to entice these retailers to change locations. Thus, overall, our results illustrate many of the relevant issues about big box development, although the analysis abstracts away from some heavily criticized features of big boxes.

The remainder of this paper is organized as follows. Section 2 outlines the standard model of the closed monocentric linear city without a big box retailer. Section 3 adds the big box to the model and derives the equilibrium output prices, land rents, retail profits, and household utility. Section 4 compares the models with and without the big box to assess the local economic effects. Section 5 offers concluding remarks.

\section{BASELINE MODEL: THE URBAN ECONOMY WITHOUT A BIG BOX}

In this section we develop a benchmark urban model without a big box retailer. The model is of a monocentric city with an exogenously determined CBD as in Fujita and Thisse (2002). We assume that the city occupies a subset of the real line $\mathfrak{R}=(-\infty, \infty)$ where consumers and firms can locate. The CBD (which we also call "downtown") is located at the point $x=0$ in the linear space, and there is a continuum of $F_{D}$ identical competitive firms clustered in the CBD. The land available in the CBD is given by $\delta$, and therefore each CBD firm uses $\delta / F_{D}$ units of land. (We use the " $D$ " subscript to distinguish downtown parameters from the big box parameters to be introduced in the next section.) There is a continuum of $N$ identical households populating the subset $\mathrm{Y}=(-\infty, \infty) \backslash\{0\}$ of the linear space. The land available at each point in $Y$ is $\delta$. Since the population is fixed, our model is a closed-city model.

Each competitive CBD firm takes the price of output $p_{D}$ as given and has the profit function $\pi_{D}\left(q_{D}\right)=p_{D} q_{D}-0.5 c_{D} q_{D}^{2}-R_{D} \delta / F_{D}$, where $q_{D}$ is output, $c_{D}$ is a marginal cost parameter, and $R_{D}$ is the rent per unit of land in the CBD (and thus each firm pays land rent $R_{D} \delta / F_{D}$ ). ${ }^{1} \mathrm{We}$ assume for simplicity that land rent is the only fixed cost. By solving the first order conditions for the firm's profit-maximizing quantity we obtain $q_{D}{ }^{*}=p_{D} / c_{D}$, so that the total quantity of output supplied by CBD firms is $Q_{D}{ }^{s *}=F_{D} p_{D} / c_{D}$. Substituting the profit-maximizing quantity back into the profit function, we find that maximum profits are equal to $\pi_{D}{ }^{*}=0.5 p_{D}{ }^{2} / c_{D}-$

\footnotetext{
${ }^{1}$ The quadratic cost function is strictly convex, so that marginal and average costs are strictly increasing. Strictly convex cost functions have been employed elsewhere in the urban literature (Fujita and Thisse, 2002). With a cubic cost function, which displays U-shaped marginal and average cost curves, the results in this section are unchanged except the number of consumers $N$ must be sufficiently large to guarantee the existence of an equilibrium price. Also, there is no closed-form solution for the equilibrium price.
}

(C) Southern Regional Science Association 2010. 
$R_{D} \delta / F_{D}$. Observe that in order to obtain a parametric expression for the maximum profit, it is necessary to know the CBD rent $R_{D}$. We assume that this rent is equal to the rent that would prevail in the absence of a downtown retail development, which is the opportunity cost of land or the agricultural land rent (denoted $R_{A}$ ). The reason for this assumption is that without the retail development the linear space would simply be a featureless plain where only agricultural activities are performed. ${ }^{2}$ It follows then that maximum profits are equal to $\pi_{D}{ }^{*}=0.5 p_{D}{ }^{2} / c_{D}-$ $R_{A} \delta / F_{D}$. We assume that $R_{A}$ is sufficiently low that $\pi^{*}$ is non-negative.

Each household has a utility function over consumption of the good produced by the CBD firms and a numeraire commodity whose price is normalized to 1. Households also obtain utility from the experience of shopping downtown, which is expressed by an "amenity" parameter that enters the utility function additively. Letting $q$ denote consumption of the output good, $z$ the consumption of the numeraire, and $A$ the utility value of the downtown shopping amenity, the utility function is assumed to be of the form $U(q, z)=u \ln (q)+z+A$, where $u$ is a marginal utility parameter. ${ }^{3,4}$ Let the household's location in the linear space be $y \in Y$, let $R(y)$ denote the rent per unit of land at $y$, and assume that each household has a perfectly inelastic demand for 1 unit of land. Then $R(y)$ measures the household's total expenditures on land rent.

Travel costs also enter the model because households must travel to the CBD in order to purchase the output produced by the CBD firms. We assume that the household incurs a roundtrip travel cost of $t$ per unit of distance traveled, which means the total round-trip travel cost incurred by a household located at $y$ is $t|y|$. Letting $I$ denote household income (assumed to be exogenous and the same for all households), the household budget constraint is $I=\mathrm{z}+p_{D} q+t|y|$ $+R(y) .^{5} \quad$ (Note that all households must buy the consumption good from downtown firms.) Therefore, consumption of the numeraire is $z=I-p_{D} q-t|y|-R(y)$. Substituting the expression for the numeraire directly into the utility function yields the household's utility as a function of consumption and location: $\widetilde{U}(q, y)=u \ln q+I-p_{D} q-t|y|-R(y)+A$.

Solving the first order condition $0=\partial \widetilde{U} / \partial q$ with respect to $q$ yields the utilitymaximizing quantity for an individual household $q^{h *}=u / p_{D}$, which implies that the total market demand for CBD-produced goods is $Q_{D}{ }^{d *}=N u / p_{D}$ (since the number of households is $N$ ). ${ }^{6}$

\footnotetext{
2 This assumption can be made into a result by assuming that the retail firms in the CBD are collectively represented by a powerful real estate bargaining agent who successfully extracts from land developers all the surplus of the retail development. Such an outcome is reasonable given a perfectly inelastic supply of land in the CBD. We could alternatively make the opposite assumption that land developers charge sufficiently high rent to extract all economic profit from CBD firms without affecting most our key results.

${ }^{3}$ The results of this section are not sensitive to the use of an additive rather than multiplicative amenity.

${ }^{4}$ Our results are not sensitive to the use of a natural $\log$ utility function. The key is that the function displays diminishing marginal utility in consumption. For instance, if we use $U(q, z)=q+z+A$, where $<1$ is the marginal utility parameter, the results below remain the same except the specific functional forms of the demand functions and prices in Results 1 and 2 must be modified accordingly. Also, existence of equilibrium prices in the model with a big box requires the number of consumers to be sufficiently large.

${ }^{5}$ According to this formulation of the budget constraint, numeraire consumption can be negative, which means that the budget constraint is effectively non-binding. This is an accepted assumption in the New Urban Economics literature (e.g., Peng and Tabuchi, 2007). For simplicity, we assume that income is sufficiently large to guarantee non-negative numeraire consumption in equilibrium.

${ }^{6}$ Notice that location does not matter for individual or aggregate demand, since neither transportation costs nor land rent enters the utility function. Each of these items, in addition to the urban amenity, has an implicit marginal disutility of -1 , making them all perfect substitutes. Ohta, Lin, and Naito (2005) show that uniform delivered pricing can emerge in equilibrium when there are scale economies in production, even without assuming analytically identical land rent and transportation costs.
}

(C) Southern Regional Science Association 2010. 
Substituting $q^{h *}$ for $q$ in $\widetilde{U}$ yields the household's indirect utility as a function of output price and location: $V\left(p_{D}, y\right)=u[\ln u-1]-u \ln p_{D}+I-t|y|-R(y)+A$. Because the households are identical, they must earn the same level of utility in equilibrium, regardless of their residential location. Letting $V^{*}$ denote the common equilibrium level of utility and solving for $R(y)$, we obtain the following expression for the residential rent function: $R *(y)=u[\ln u-1]-u \ln p_{D}+I-t|y|-V^{*}+A$.

We can find the market-clearing price of downtown-produced output by setting the downtown supply equal to the demand $\left(Q_{D}{ }^{\mathrm{s} *}=Q_{D}{ }^{{ }^{*}}\right)$ and solving for $p_{D}{ }^{*}$. This yields $p_{D}{ }^{*}=\left(N u c_{D} / F_{D}\right)^{1 / 2}$. If we substitute $p_{D} *$ into the profit and residential rent functions we obtain:

$$
\begin{aligned}
& \pi_{D}^{*}=0.5 N u / F_{D}-R_{A} \delta / F_{D}, \\
& R *(y)=u\left[0.5 \ln \left(u F_{D} / N c_{D}\right)-1\right]+I-t|y|-V^{*}+A .
\end{aligned}
$$

It is possible to solve for the equilibrium value of household utility $V^{*}$ by noting that at the boundaries of the residential district, the residential rent must equal the opportunity cost of land $R_{A}$. Since the number of households in the economy is $N$ and the amount of available land is $\delta$ at each location, a symmetric arrangement of households around the CBD implies that the left and right boundary points of the city are $-N / 2 \delta$ and $N / 2 \delta$, respectively. Therefore, imposing the boundary conditions and solving for $V^{*}$ we have:

$$
V^{*}=u\left[0.5 \ln \left(u F_{D} / N c_{D}\right)-1\right]+I-t N / 2 \delta-R_{A}+A .
$$

Substituting this expression for $\mathrm{V}^{*}$ into (2) yields:

$$
R *(y)=\mathrm{R}_{\mathrm{A}}+t[N / 2 \delta-|y|] .
$$

Therefore, the residential rent function decreases linearly with slope $t$ in either direction away from the CBD. In Figure 1 we show the land rent profile for the urban economy with a competitive cluster of CBD firms.

\section{THE URBAN ECONOMY WITH A BIG BOX}

We now expand the model developed in Section 2 to include a big box retailer that differs from the small local retailers in both size and marginal production costs. Note that, since households may have difficulty changing their locations over a short span of time, a comparison of this model with the one developed in Section 2 may most appropriately be viewed as illustrating changes in household locations and land values that arise after sufficient time has elapsed for households to respond to the entry of the big box. In other words, the model presented in this section describes the "long run" effects of the big box on the local economy.

For simplicity we will assume that the big box retailer prices competitively, although the implications of relaxing this assumption are discussed briefly below. Specifically, the big box firm is larger than the local retailers (in the sense that it is the only firm operating at its location, which has the same amount of land as the CBD) and has a cost advantage over its competitors. Because the analysis is rather involved when there are marginal cost differences between retailers, we abstract away from labor markets by assuming that residents receive income exogenously and that the firms in the model use only non-labor variable inputs. The examination 


\section{FIGURE 1: Land Rent Profile without Big Box Retailer}

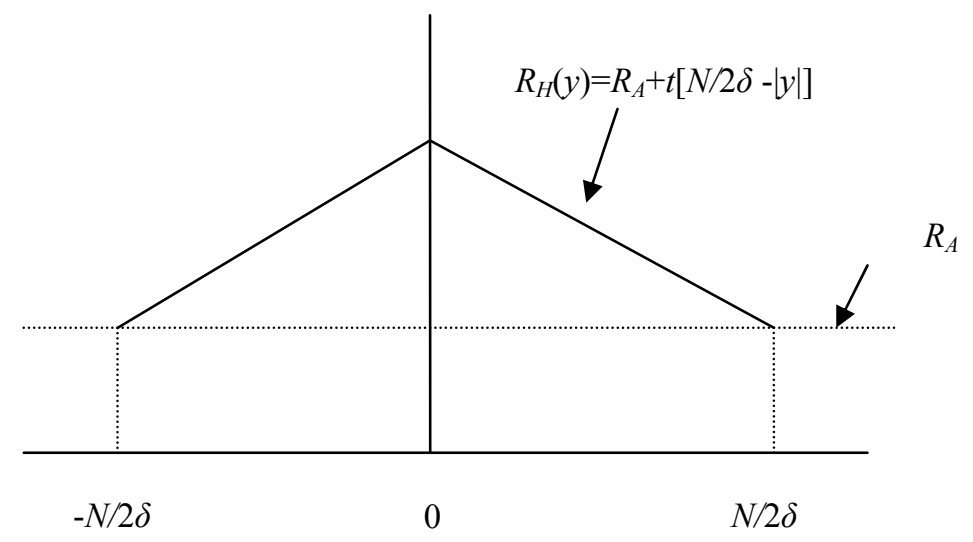

of big box retail effects on local labor markets is an important item on the agenda for future research.

As in the previous model, the small local retailers operate in the CBD only. The total number of these retailers is $F_{D}$, and each of them has the profit function $\pi_{D}\left(q_{D}\right)=p_{D} q_{D}-$ $0.5 c_{D} q_{D}{ }^{2}-R_{D} \delta / F_{D}$, where $p_{D}$ is the price of output sold in the CBD, $q_{D}$ is the amount of output produced by a particular downtown firm, $c_{D}>0$ is a marginal cost parameter, and $R_{D}$ is the rent per unit of land in the CBD. The profit-maximizing quantity of output for each CBD firm is therefore $q_{D}{ }^{*}=p_{D} / c_{D}$ and the market supply of output in the CBD is $Q_{D}{ }^{s}=F_{D} p_{D} / c_{D}$. Each of these firms earns maximum profits of $\pi_{D}{ }^{*}=0.5 p_{D}{ }^{2} / c_{D}-R_{A} \delta / F_{D}$, where we have substituted the opportunity cost of land $R_{A}$ for the CBD rent $R_{D}$ as in the model in Section 2.

We assume that a big box retailer has chosen to locate at a point $L>0$. While this location is treated as exogenous at the moment, we will discuss the socially and privately optimal choices of $L$ later in the paper. The big box retailer is assumed to consist of $F_{B}$ production units, where $F_{B}$ is not necessarily equal to $F_{D}$, with each unit having the cost function $C_{B}\left(q_{B}\right)=$ $0.5 c_{B} q_{B}^{2}$, where $q_{B}$ is the quantity of output produced and $c_{B}$ is a marginal cost parameter. ${ }^{7}$ For any given amount of output $Q$, we assume that the management of the big box retailer coordinates production among the various units in order to minimize cost. This involves assigning the output $Q / F_{B}$ to each production unit.

Observe that $Q$ units of output can be produced in the CBD at a minimum total cost $0.5 c_{D}\left(Q^{2} / F_{D}\right)$, which occurs with each firm producing $Q / F_{D}$ units, and can be produced at the big box at a minimum total cost $0.5 c_{B}\left(Q^{2} / F_{B}\right)$, which occurs with each production unit producing $Q / F_{B}$. The big box then has a cost advantage over the CBD if $c_{B}<\left(F_{B} / F_{D}\right) c_{D}$. Thus, the big box marginal cost must be lower than the marginal cost of any given CBD firm by at least the factor

\footnotetext{
${ }^{7}$ With cubic cost functions that exhibit economies of scale, the results in this section are largely unchanged, except that the existence of equilibrium prices becomes more difficult to formally establish. Proving the result that we express in Proposition 2 (a lower equilibrium price for the big box) also requires a more involved set of assumptions - that the big box has a quadratic cost coefficient that is at least $\left(F_{B} / F_{D}\right)$ times that of a CBD firm and a cubic cost coefficient that is no more than $\left(F_{B} / F_{D}\right)^{2}$ times that of a CBD firm.
}

(C) Southern Regional Science Association 2010. 
$F_{B} / F_{D}$. To guarantee an overall efficiency advantage for the big box, we impose this assumption for the rest of our discussion. ${ }^{8}$

The profit function for the big box, when production is divided up among the various units to minimize cost, is $\pi_{B}\left(Q_{B}\right)=p_{B} Q_{B}-0.5 c_{B} Q_{B}{ }^{2} / F_{B}-R_{B}(L) \delta$, where $p_{B}$ is the price of output sold by the big box, $R_{B}(L)$ is the rent the big box retailer pays per unit of land at location $L$ and $R_{B}(L) \delta$ is therefore the total rent the retailer pays for using $\delta$ units of land. We assume that (as for the CBD firms) the retailer pays the rent that would prevail at its location if it did not exist. For a location $L$ in the interval $(0, N / 2 \delta)$, the rent is therefore $R_{B}(L)=R_{A}+t[N / 2 \delta-L]$, while for $L$ $\epsilon(N / 2 \delta, \infty)$, the rent is $R_{B}(L)=R_{A}$.

We assume that the big box retailer prices competitively. Thus, it maximizes $\pi_{B}$ with respect to $Q_{B}$ while taking $p_{B}$ as parametric. ${ }^{9}$ Under competitive pricing, the profit-maximizing output for the big box is $Q_{B}^{*}=F_{B} p_{B} / c_{B}$, which is also the market supply of output at the big box, $Q_{B}{ }^{s}$. Maximum profits are then $\pi_{B}{ }^{*}=0.5 F_{B} p_{B}{ }^{2} / c_{B}-R_{B}(L) \delta / F_{B}$.

In order to establish the existence of market-clearing prices at the downtown and big box retail nodes, it is necessary to compute the market demand functions for downtown and big box output. This requires a correspondence between household residential locations and shopping destinations. Accordingly, suppose that each household that shops downtown has the utility function $U_{D}\left(q_{D}{ }^{h}, z\right)=u \ln \left(q_{D}{ }^{h}\right)+z+A$ and the budget constraint $I=\mathrm{z}+p_{D} q_{D}{ }^{h}+t|y|+R_{D}(y)$, where $q_{D}{ }^{h}$ is the household's consumption of the downtown good, $R_{D}(y)$ is the residential rent per unit of land charged to downtown shoppers located at $y$, and all other parameters are defined as above. ${ }^{10}$

Each household that shops at the big box has the utility function $U_{B}\left(q_{B}{ }^{h}, z\right)=u \ln \left(q_{B}{ }^{h}\right)+z$ and the budget constraint $I=\mathrm{z}+p_{B} q_{B}{ }^{h}+t|L-y|+R_{B}(y)$, where $q_{B}{ }^{h}$ is the household's consumption of the big box good and $R_{B}(y)$ is the per-unit land rent charged to big-box shopping households residing at point $y$. Thus, observe that the utility functions and budget constraints differ in the presence or absence of the downtown amenity and in the travel distance to the shopping destination.

If we substitute the budget constraints directly into the utility functions, we can rewrite utility for downtown and big box shoppers as the following functions of consumption and residential location:

\footnotetext{
${ }^{8}$ The number $c_{D} / F_{D}$ can be thought of as the "effective marginal cost" for the group of downtown firms, because if another unit of output were to be produced downtown at minimum additional cost, each firm would produce $1 / F_{D}$ additional units, resulting in the marginal cost $c_{D} / F_{D}$. Similarly, $c_{B} / F_{B}$ is the effective marginal cost for the big box. Therefore, the assumption $c_{B}<\left(F_{B} / F_{D}\right) c_{D}$ merely requires that the effective marginal cost be lower for the big box than for the CBD. This notion is consistent with the opinions of some industry experts that Wal-Mart is "orders of magnitude" more efficient than its competitors (Jiminez, 1990; Malkin, 2004).

${ }^{9}$ This assumption could be relaxed without affecting our central results, except that proving Proposition 2 (a lower equilibrium price for the big box) would require sufficiently lower marginal costs for the big box to offset the incentive to exploit market power by charging a higher price.

${ }^{10}$ The amenity captures utility differences in the act of shopping at a downtown versus a big box store. Thus, it can broadly be interpreted as capturing product differences between the two goods. However, because it enters the utility function additively, it best reflects differences in the shopping environment at the two retail locations, as opposed to differences in the characteristics of the products sold. In order to model inherent product differences (such as a lower quality product at the big box), one could instead enter the amenity term multiplicatively so that it affects marginal utility, for instance in the form $(u+A) \ln (q)$. In this case, the utility difference between downtown and big box shopping increases with quantity purchased. This does not alter our conclusions about the effects of big box entry or changes in its location. However, an additional assumption is required to show that the downtown firms charge the higher equilibrium price.
}

(C) Southern Regional Science Association 2010. 


$$
\begin{aligned}
& \widetilde{U}_{D}\left(q_{D}^{h}, y\right)=u \ln q_{D}^{h}+I-p_{D} q_{D}^{h}-t|y|-R_{D}(y)+A, \\
& \widetilde{U}_{B}\left(q_{B}^{h}, y\right)=u \ln q_{B}^{h}+I-p_{B} q_{B}^{h}-t|L-y|-R_{B}(y) .
\end{aligned}
$$

Maximizing (5) and (6) with respect to quantity, we find that the utility-maximizing quantity of consumption goods is $q_{D}{ }^{h} * u / p_{D}$ for a downtown shopping household and $q_{B}{ }^{h_{*}}=u / p_{B}$ for a big box shopping household. It follows that the total market quantity of downtown goods demanded is $Q_{D}{ }^{d}=N_{D}\left[u / p_{D}\right]$ and the total market quantity of big box goods demanded is $Q_{B}{ }^{d}=N_{B}\left[u / p_{B}\right]$, where $N_{D}$ and $N_{B}$ are the numbers of consumers that choose to shop downtown and at the big box, respectively. ${ }^{11}$ (The values of $N_{D}$ and $N_{B}$ depend on the relative prices of downtown and big box goods as shown below.)

If we substitute the optimal consumption quantities $q_{D}{ }^{h} * u / p_{D}$ and $q_{B}{ }^{h_{*}}=u / p_{B}$ into (5) and (6), we obtain the indirect utility functions of downtown and big box shopping households in terms of prices and residential location:

$$
\begin{aligned}
& V_{D}\left(p_{D}, y\right)=u[\ln u-1]-u \ln p_{D}+I-t|y|-R_{D}(y)+A, \\
& V_{B}\left(p_{B}, y\right)=u[\ln u-1]-u \ln p_{B}+I-t|L-y|-R_{B}(y) .
\end{aligned}
$$

In order for there to be positive numbers of shoppers at each location, we must have:

$$
\exp \left(\frac{A-t L}{u}\right)<\frac{p_{D}}{p_{B}}<\exp \left(\frac{A+t L}{u}\right) .
$$

This condition is derived in the Appendix. Intuitively, the downtown-to-big-box price ratio must be sufficiently large relative to the amenity net of the additional cost of traveling downtown, or no one will want to shop at the big box. At the same time, the amenity plus the travel cost savings of shopping downtown must be sufficiently large relative to the downtown-to-big-box price ratio, or no one will want to shop downtown.

A household located at $y$ will prefer downtown to big box shopping if $V_{D}\left(p_{D}, y\right)>$ $V_{B}\left(p_{B}, y\right)$. Thus, given the indirect utility functions (7) and (8) and condition (9), households at all locations $y<0$ will shop downtown and households at all locations $y>L$ will shop at the big box. If $0<y<L$, downtown shopping is preferred if $y<y^{*}$, where $y^{*}$ is defined by:

$$
y^{*}=(L / 2)+(A / 2 t)-(u / 2 t) \ln \left(p_{D} / p_{B}\right) .
$$

(Note that condition (9) guarantees that $0<y^{*}<L$.) Thus, $y^{*}$ is the "shopping cutoff" location in the sense that all households living to the left of $y^{*}$ shop downtown and all households living to the right of $y^{*}$ shop at the big box. The cutoff is definitely closer to the big box than to downtown (so that the market area of the downtown firms is larger than the market area of the big box) if $p_{D}<p_{B}$, but could still be closer to the big box even in the event that $p_{D}>p_{B}$ if $A$ is sufficiently large.

\footnotetext{
${ }^{11}$ Notice that location does not matter for individual or aggregate demand, as in the model without a big box. Expenditures will be the same for any two households traveling to the same retail location. Location only matters in the sense that household expenditure can differ based on shopping destination, which is determined by location.
}

(C) Southern Regional Science Association 2010. 
The next step is to determine the numbers of consumers $N_{D}$ and $N_{B}$ who shop at each retail location. These values are provided in the following result, the proof of which is given in the Appendix.

Proposition 1: The numbers of consumers $N_{D}$ and $N_{B}$ shopping downtown and at the big box, respectively, are: $N_{D}=N / 2-(\delta u / t) \ln \left(p_{D} / p_{B}\right)+(\delta A / t)$ and $N_{B}=N / 2+(\delta u / t) \ln \left(p_{D} / p_{B}\right)-(\delta A / t)$. Thus, downtown attracts more customers relative to the big box as the downtown amenity $A$ increases or the downtown-to-big-box price ratio $p_{D} / p_{B}$ decreases.

The market-clearing conditions for the CBD and the big box are obtained by equating $Q_{D}{ }^{s}=Q_{D}{ }^{d}$ and $Q_{B}{ }^{s}=Q_{B}{ }^{d}$, respectively. Using Proposition 1 to compute the demand functions, the resulting conditions are:

$$
\begin{aligned}
& \frac{F_{D} p_{D}^{2}}{c_{D} u}=\frac{N}{2}-\left(\frac{\delta u}{t}\right) \ln \left(\frac{p_{D}}{p_{B}}\right)+\left(\frac{\delta A}{t}\right) \\
& \frac{F_{B} p_{B}^{2}}{c_{B} u}=\frac{N}{2}+\left(\frac{\delta u}{t}\right) \ln \left(\frac{p_{D}}{p_{B}}\right)-\left(\frac{\delta A}{t}\right)
\end{aligned}
$$

Equation (11) implies that for a particular positive value of $p_{B}$, there is a unique positive solution $p_{D}\left(p_{B}\right)$ that is increasing, continuous, concave, and converges to zero as $p_{B}$ approaches zero. Concavity can be verified by implicitly differentiating (11) twice with respect to $p_{D}$ and $p_{B}$ and noting that $d p_{D} / d p_{B}>0$ while $d^{2} p_{D} / d p_{B}{ }^{2}<0$. It can likewise be demonstrated that there is a unique solution $p_{B}\left(p_{D}\right)$ to (12) that is increasing, continuous, concave, and converges to zero as $p_{D}$ approaches zero. Consequently, if we place the graphs of $p_{D}$ and $p_{B}$ on the same diagram (as in Figure 2), there is a unique intersection point between the two curves. This intersection point corresponds to the unique equilibrium price vector $\left(p_{D}^{*}, p_{B}{ }^{*}\right)$ that simultaneously clears the markets.

An interesting application of the theory is to predict the effects of model parameters on the equilibrium prices $p_{D}{ }^{*}$ and $p_{B}{ }^{*}$. This exercise can be carried out by appropriately shifting the curves in Figure 2 when a parameter of interest changes. For example, an increase in the number of CBD firms $F_{D}$ decreases both the downtown and big box prices because the supply of downtown goods increases, lowering the downtown price, which decreases the demand for big box goods and decreases the big box price. An increase in the number of consumers $N$ increases the demand for both big box and downtown goods, and therefore both prices increase. Increases in $c_{D}$ and $c_{B}$ lead to higher retail prices in both locations because they result in reduced supply. An increase in the value of the amenity $A$ increases the equilibrium downtown price and decreases the equilibrium big box price because it raises the willingness to pay for downtown goods, which increases the downtown price. However, the increase in the downtown price also raises the big box demand as some consumers substitute toward the big box, increasing the big box price.

Another useful result is obtained by using the quotient rule and the derivatives $d p_{D} * / d A$ and $d p_{B} * / d A$ to calculate the derivative of the natural log of the downtown-to-big-box price ratio with respect to $A$. It turns out that $\mathrm{d} u \cdot \ln \left(p_{D}{ }^{*} / p_{B}{ }^{*}\right) / \mathrm{d} A<1$. Intuitively, this condition holds both because of the slow growth of the natural $\log$ function and because $A$ is only one of many factors that affects prices, so the impact on the price ratio is small compared to the growth in $A$

(C) Southern Regional Science Association 2010. 


\section{FIGURE 2: “Reaction Curves” for Downtown and Big Box}

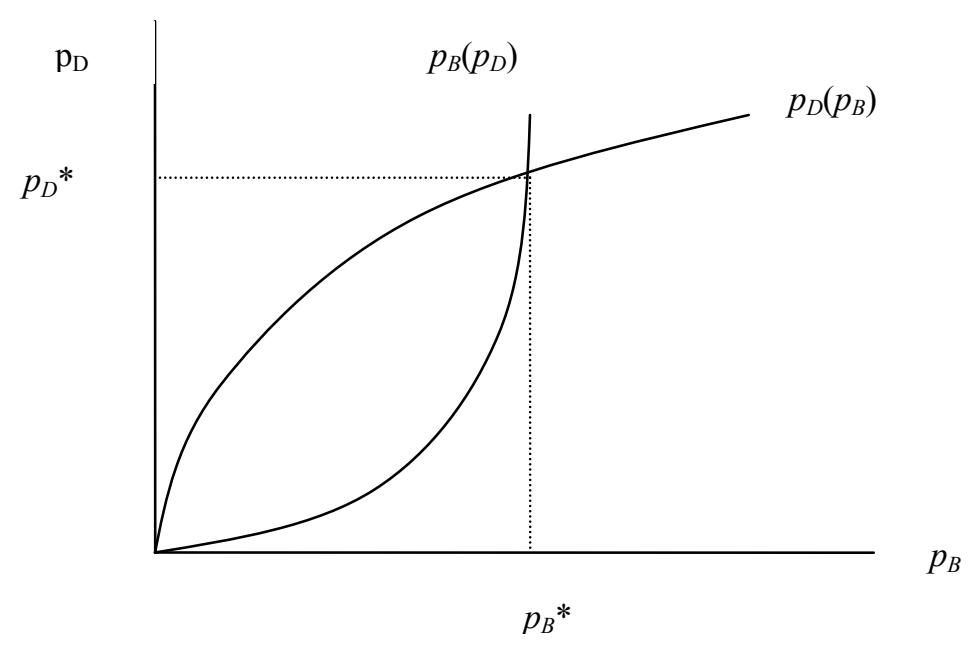

itself. Although seemingly innocuous, this result is actually quite important because it implies it is possible to choose $A$ sufficiently large that:

$$
A>u \ln \left(p_{D} * / p_{B} *\right) \text {. }
$$

As we show in the Appendix, (13) guarantees that the limit of the residential rent approaching the city center is larger than the limit of the residential rent approaching the big box location (a result in accord with the observation that land values in city centers tend to be larger than land values near big box retailers). Intuitively, (13) is needed because if $A$ is not sufficiently large compared to the price differential between downtown and big box goods, then living downtown is not sufficiently attractive to drive the downtown rent higher than the big box rent.

Assumption (13) also implies that in equilibrium, the ratio of the downtown price to the big box price is bounded below by a monotonic function of the ratio of the effective downtownto-big-box marginal cost. We state this result in the following proposition, the proof of which is given in the Appendix.

Proposition 2: In equilibrium, the big box charges a lower price than the downtown firms: $p_{B} *<$ $p_{D}{ }^{*}$. If assumption (13) also holds, then the ratio of the downtown to the big box price is bounded below by a monotonic function of the ratio of the downtown to the big box marginal cost:

$$
\frac{p_{D} *}{p_{B} *}>\sqrt{\frac{F_{B}}{F_{D}} \frac{c_{D}}{c_{B}}}>1 .
$$

Thus, the big box price discount relative to the downtown price is at least as large as (the square root of) the relative marginal cost advantage for the big box. By "relative marginal cost advantage" we mean the ratio of the effective downtown marginal cost $\left(c_{D} / F_{D}\right)$ to the effective big box marginal cost $c_{B} / F_{B}$. We emphasize that assumption (13) is not required for proving that $p_{D}{ }^{*}>p_{B}{ }^{*}$, as the proof illustrates. Indeed, the downtown price would be higher than the big box price even with no downtown amenity.

(C) Southern Regional Science Association 2010. 
Having established the existence of well-defined equilibrium prices (albeit not in closed form) and a means of examining the effects of model parameters on these prices, we are now in a position to derive the equilibrium land rent function when there is a big box retailer. We will ultimately use this to derive an expression for equilibrium household utility and examine how utility depends on the location of the big box.

Evaluating the indirect utility expressions (7) and (8) at the equilibrium prices and using the fact that all households earn the same equilibrium utility (denoted $V^{*}$ ), we obtain expressions for the equilibrium land rent functions in the two shopping districts:

$$
\begin{gathered}
R_{D} *(y)=u[\ln u-1]-u \ln p_{D} *+I-t|y|+A-V^{*}, \\
R_{B} *(y)=u[\ln u-1]-u \ln p_{B} *+I-t|L-y|-V^{*} .
\end{gathered}
$$

An expression for $V^{*}$ in terms of prices and parameters can be derived by imposing the boundary rent conditions on the functions in (15) and (16). These conditions state that the equilibrium rent at the city's left and right boundary points $B_{L}$ and $B_{R}$ is equal to the agricultural rent. Expressions for $B_{L}$ and $B_{R}$ are provided in the proof of Proposition 1. Imposing the conditions $R_{D} *\left(B_{L}\right)=R_{A}$ and $R_{B} *\left(B_{R}\right)=R_{A}$ and solving for $V^{*}$ yields:

$$
V^{*}=u[\ln u-1]-\frac{u}{2} \ln \left(p_{D} * p_{B} *\right)+I+\frac{A}{2}-\frac{t}{2}\left[\frac{N}{\delta}-L\right]-R_{A} \text {. }
$$

Thus, equilibrium utility is decreasing in the prices of retail goods, increasing in household income, increasing in the downtown amenity, decreasing in the travel cost (note that $N / \delta>L$ must hold for $B_{R}>L$; otherwise there is vacant land between the two shopping districts in equilibrium), decreasing in the population size, increasing in the amount of available land, and decreasing in the opportunity cost of land. Utility is also increasing as the big box locates further away from downtown because such a movement by the retailer reduces the competition for land between the retail centers.

Substituting $V^{*}$ into the expressions (15) and (16) and simplifying yields the equilibrium land rent functions:

$$
\begin{aligned}
& R_{D} *(y)=R_{A}+\frac{t}{2}\left[\frac{N}{\delta}-L\right]+\frac{A}{2}+\frac{u}{2} \ln \left(p_{B}^{*}\right)-\frac{u}{2} \ln \left(p_{D}^{*}\right)-t|y|, \\
& R_{B} *(y)=R_{A}+\frac{t}{2}\left[\frac{N}{\delta}-L\right]-\frac{A}{2}+\frac{u}{2} \ln \left(p_{D}^{*}\right)-\frac{u}{2} \ln \left(p_{B}^{*}\right)-t|L-y| .
\end{aligned}
$$

Thus, in each of the shopping zones the residential rent function peaks at the shopping center and decreases linearly at the rate $t$ away from the shopping center. As we show in the Appendix, the peak of the downtown rent function $R_{D}{ }^{*}(0)$ is higher than the peak of the big box rent function $R_{B}{ }^{*}(L)$ if and only if (13) holds. Figure 3 shows the equilibrium land rent profile.

To see what happens to the land rent profile when there is an increase $L$, observe that the left and right city boundary points in the figure will move to the right, as will the shopping cutoff point. The peak of the downtown residential rent will remain at the CBD (but will be lower) and 


\section{FIGURE 3: Land Rent Profile with a Big Box Retailer}

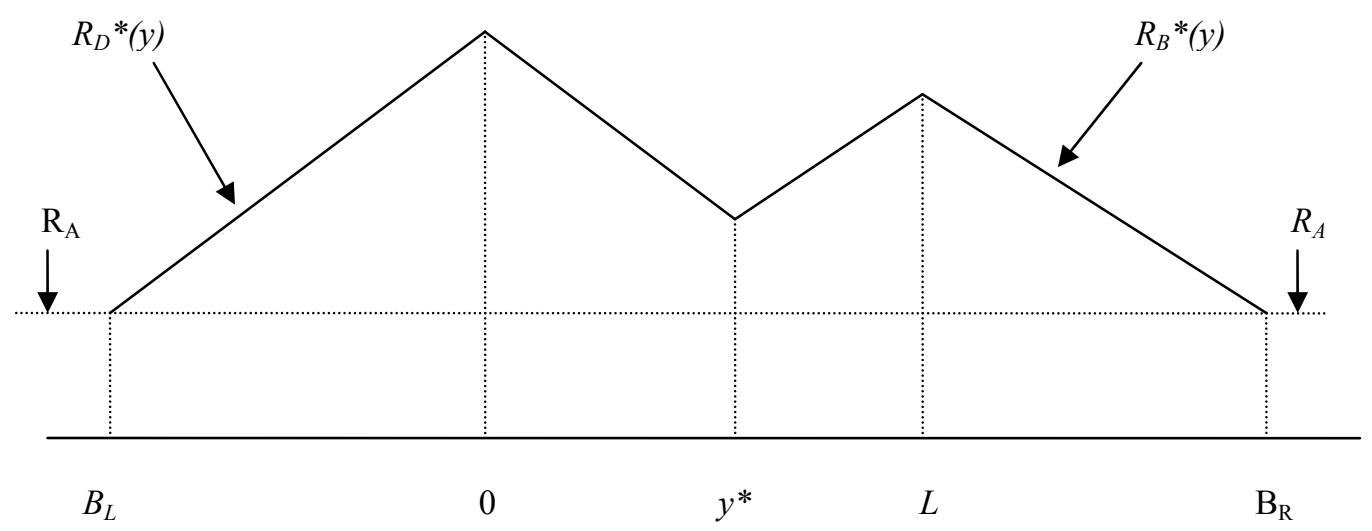

the peak of the big box residential rent will move to the right (and will also be lower). ${ }^{12}$ Land values fall everywhere to the left of the original $L$ and rise everywhere to the right of the new $L$. In fact, it can be demonstrated that there is a cutoff point $y^{\prime}$ such that land values decrease at all locations left of $y^{\prime}$ and increase at all locations right of $y^{\prime}$. This cutoff point satisfies $y^{\prime}=(1 / 4) L_{1}+$ (3/4) $L_{2}$, where $L_{1}$ is the old location and $L_{2}$ is the new location. The details of the calculation are in the Appendix.

A natural question concerns how the big box location $L$ is chosen. One possibility is that the big box chooses a profit-maximizing location. Recall that the maximum profits for the big box are $\pi_{B}{ }^{*}=0.5 F_{B} p_{B}^{2} / c_{B}-R_{B}(L) \delta / F_{B}$, where $R_{B}(L)=R_{A}+t N / 2 \delta-t L$ if $L \epsilon(0, N / 2 \delta)$ and $R_{B}(L)=$ $R_{A}$ if $L \in[N / 2 \delta, \infty)$. Since the market clearing conditions are independent of $L$, equilibrium prices are independent of $L$. This implies that the big box profit is increasing with distance to the CBD (up to $N / 2 \delta$ ) because land rents are cheaper. Thus, any location greater than or equal to $N / 2 \delta$ is profit-maximizing. This may help explain why we do not often see large retail developments close to downtown areas.

One could alternatively explain this result by assuming the choice of a big box location $L$ represents the economic interests of local agents (e.g., through a zoning process administered by a local government influenced by voters as in Rhee, 2004). The equilibrium utility of households given in (17) is increasing in $L$, which means they will want to locate the big box as far away from the CBD as possible (at least up to the point $N / 2 \delta$ after which they are indifferent to further increases in $L$ because the sizes of the shopping zones cease to change). Thus, the preferences of local households concerning big box location coincide with the interests of the retailer. Given that a big box enters the economy, downtown merchants actually do not care where it locates because their profits are independent of $L$. Changes in $L$ simply lead to compensating changes in the city's boundary points such that the market area of downtown firms is unchanged.

\footnotetext{
${ }^{12}$ These observations imply there is a transfer of surplus from CBD land owners to households.
}

(C) Southern Regional Science Association 2010. 
Therefore, regardless of whether $L$ is the result of profit-maximizing location decisions or utilitymaximizing land-allocation decisions, $L$ will be at least as large as $N / 2 \delta .^{13}$

In summary, we have the following result concerning changes in big box location.

Proposition 3: If the distance between the CBD and the big box increases, equilibrium household utility and big box profits increase. Land values decrease at all points to the left of the original big box location and increase at all points to the right of the new location. The cutoff point where land values start to increase is closer to the new big box location than to the original one. The profits of the big box and the utility of local residents are maximized at any location that is at least as large as $N / 2 \delta$.

\section{COMPARING THE URBAN ECONOMY WITH AND WITHOUT A BIG BOX}

In this section we compare the equilibrium values of downtown firm profits, household utility, and urban land values before and after the entry of the big box. For downtown firms, profits are equal to $0.5 p_{D} *^{2} / c_{D}-R_{A} \delta / F$ when there is no big box retailer and are equal to this same expression when there is one. Thus, the entry of the big box retailer reduces the profits of these firms if and only if it reduces the price of downtown goods. Using the market-clearing conditions, it can be demonstrated that downtown prices are lower after the entry of the big box if and only if:

$$
A<(t N / 2 \delta)+u \ln \left(p_{D} * / p_{B}{ }^{*}\right) .
$$

Thus, as long as the value of the amenity is not excessively large, the entry of the big box reduces the prices of goods sold downtown and the profits of downtown merchants. This may help explain the typical opposition of local merchants to big box development. ${ }^{14}$

Consider now the manner in which the equilibrium utility of households is affected by the entry of the big box. In the absence of the large retailer, households earn utility equal to $V^{*}$ before $=u[\ln (u)-1]-u \ln \left(p^{*}\right)+I-t N / 2 \delta-R_{A}+A$, where $p^{*}$ is the equilibrium downtown price when there is no big box. After the entry of the big box, households earn utility of $V^{*}{ }_{\text {after }}=u[\ln (u)-1]$ $-(u / 2) \ln \left(p_{D}{ }^{*}\right)-(u / 2) \ln \left(p_{B}{ }^{*}\right)+I-t N / 2 \delta+t L / 2-R_{A}+(A / 2)$, where $p_{D}{ }^{*}$ and $p_{B}{ }^{*}$ are the equilibrium output prices when there is a big box. It follows that utility is higher after the entry of the big box than before if $(A / 2)+(u / 2) \ln \left(p_{D}{ }^{*}\right)+(u / 2) \ln \left(p_{B}{ }^{*}\right)<u \ln \left(p^{*}\right)+t L / 2$. Note that because $p_{B}{ }^{*}<p_{D}{ }^{*}$ (Proposition 2) and $p_{D}{ }^{*}<p^{*}$ by the discussion above, we have $(A / 2)+$ $(u / 2) \ln \left(p_{D}{ }^{*}\right)+(u / 2) \ln \left(p_{B}^{*}\right)<(A / 2)+u \ln \left(p^{*}\right)$. Thus, if $A<t L$ we can definitely conclude that utility is higher after the entry of the big box than before. Utility increases after the entry of the big box for three main reasons: the existence of a lower-priced shopping alternative, a reduction in the price of downtown retail goods, and a reduction in travel costs for those who decide to

\footnotetext{
${ }^{13}$ For the rent functions to intersect each other before dropping below the agricultural rent, the big box must be in a location $L<$ $N / 2 \delta$, or further left than the utility- and profit-maximizing locations. Possible explanations of why this might occur include a lack of public infrastructure in remote locations (so that big box development cannot be supported past the original city boundary), or a distaste for vacant land on the part of public officials. It may also be that the big box desires to locate closer than $N / 2 \delta$ because cost-sharing arrangements with the local government (in the construction of infrastructure) are possible inside the original city boundary but not outside of it. Finally, the big box may not be aware of the exact profit-maximizing location when it first enters the city. Under any of these conditions the equilibrium location could be less than $N / 2 \delta$ as shown in Figures 3 and 4 (where the rent functions intersect before reaching $R_{A}$ ).

${ }^{14}$ If the amenity is sufficiently large, the entry of the big box could cause downtown prices and profits to increase. The reason is that when households have shopping alternatives, the amenity pushes up the demand for downtown goods. In contrast, when there is no big box and everyone experiences the downtown amenity, it does not enter into the demand function.
}

(C) Southern Regional Science Association 2010. 


\section{FIGURE 4: Effect of Big Box Retailer Entry on Urban Land Rent Profile}

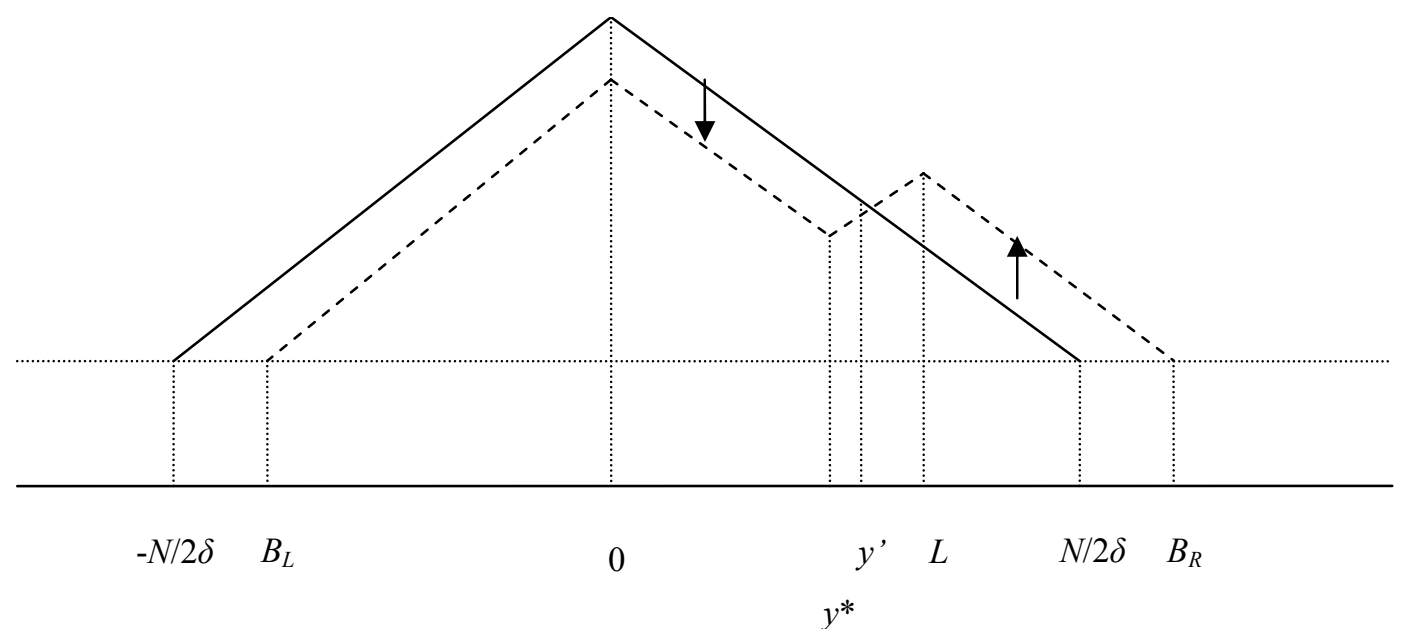

shop at the big box. However, the conclusion of higher utility does hinge on the amenity being sufficiently small relative to the cost of traveling from the CBD to the big box. Otherwise, the effect of not experiencing the amenity dominates the savings in travel cost for those who switch to shopping at the big box, and utility falls.

The entry of the big box retailer also affects land values. Figure 4 compares the rent profile when there is no big box (solid line) to the rent profile when there is a big box (dashed line). The entry of the big box reduces land values in the vicinity of the CBD and increases land values in the vicinity of the big box. (It can be shown that the cutoff point $y^{\prime}$ where land values start to increase as the result of the big box development is in the interval $[3 L / 4, L]$.) The land rent profile also becomes bimodal rather than unimodal, with peaks at the CBD and the location of the big box. ${ }^{15}$ We therefore have the following result concerning the effects of big box entry.

Proposition 4: Assuming that downtown shopping amenities are not excessively high, the entry of a big box retailer into the local economy reduces profits for downtown retailers and increases the utility of local residents. The entry of the big box reduces land values in the vicinity of the $C B D$ and increases land values in the vicinity of the big box development. The cutoff point where land values begin to increase in response to big box development is closer to the big box than to downtown.

Propositions 3 and 4 rely on the strong assumption that there are many land developers. If the land market is imperfectly competitive, there is an incentive for developers to try and attract the big box away from its present location by offering it below-market rents. This is because land values will increase in the vicinity of the new big box location, raising the developer's profits. For instance, let us model imperfect competition as each developer owning a non-trivial land segment of radius $\varepsilon>0$ and having direct control over the rent charged on this

\footnotetext{
${ }^{15}$ The diagram assumes that $L<N / 2 \delta$ (i.e., no vacant land between the shopping zones in equilibrium). However, even if there is vacant land in equilibrium because $L>N / 2 \delta$, the entry of the big box still reduces land rents in the vicinity of the CBD and raises them in the vicinity of the big box.
}

(C) Southern Regional Science Association 2010. 
segment. Further, suppose the developer is willing to offer a rent discount equal to the increase in the total value of land holdings resulting from the big box relocating to the property. Then, for the case considered here, with $L<N / 2 \delta$ and $A<t L$, the maximal rent discount among all developers in the economy occurs at the left city boundary point $B_{L}$. This is because the rent is initially lowest at the two city boundary points, so the increase in land values that results from attracting the big box is highest at these locations. Furthermore, the left boundary is closer to downtown than the right boundary, so the entry of the big box pushes land values up more at the left boundary than at the right boundary. The value of the discount offered by the developer at the left boundary point is increasing in the size of land holdings $\varepsilon$, increasing in the big box location $L$, decreasing in the downtown amenity $A$, and increasing in the downtown-to-big-boxprice ratio. The effects of the population $N$, the land density $\delta$, and the travel cost $t$ are all ambiguous. $^{16}$

The incentive for developers to offer land rent discounts may help explain the tendency for big boxes to switch locations, sometimes leaving vacant retail centers in their wake (Krause, 1999). Such moves negatively impact developers in the present location of the big box, because land values will decrease in the surrounding area. These developers have an incentive to reduce the land rent charged to the big box in order to induce it to stay. The change in land values in a neighborhood of $L$ resulting from the exit of the big box can be interpreted as the rent discount the developer at $L$ would be willing to offer to keep the big box in place. This discount is increasing in the size of land holdings, increasing in the big box location, decreasing in the downtown amenity, and increasing in the downtown-to-big-box price ratio. In deciding whether or not to relocate, the big box will compare the "net rent" at the left city boundary point (i.e., the base rent $R_{A}$ minus the developer's discount) with the net rent at $L$. It can be shown that the net rent at $B_{L}$ is always lower than the net rent at $L$, and thus the big box will relocate. This is because, although the rent discounts are similar, the base rent is much higher at the original big box location. Thus, if $L<N / 2 \delta$ and $A<t L$, big box locations are unstable if relocation is costless and the land market is imperfectly competitive. ${ }^{17}$

Just as developers may bid against each other to attract big boxes to new locations, local governments have incentives to offer subsidies and abatements to attract big box developments away from other jurisdictions (Sommer, 1995). Suppose the subsidy the local government is willing to offer equals the increase in household utility due to the entry of the big box. Then the value of the subsidy is:

$$
\Delta V^{*} \equiv V^{*}{ }_{\text {after }}-V_{\text {before }}^{*}=(u / 2) \ln \left(p^{* 2}\right)-(u / 2) \ln \left(p_{D}^{*}\right)-(u / 2) \ln \left(p_{B}^{*}\right)+t L / 2-A / 2 .
$$

The subsidy is decreasing in the downtown amenity $A$, increasing in the density of land $\delta$, and increasing in the big box location $L$. The population size $N$ has an ambiguous effect, as does the travel cost $t$. (Derivations are in the Appendix.) Thus, in view of these results, we would expect to see the largest subsidies offered in low-density cities with relatively less developed downtown shopping infrastructure, as well as in cities where proposed big box developments are relatively distant from downtown retail centers.

\footnotetext{
${ }^{16}$ The proofs of the statements made in this paragraph are omitted in the interests of brevity, but are available upon request. To verify the comparative static results for the effects of model parameters on the rent discount, one can implicitly differentiate the market-clearing conditions (11) and (12) with respect to each parameter, solve the equations simultaneously, and then apply Proposition 2.

${ }^{17}$ The proofs of the statements made in this paragraph are omitted, but available upon request.

(C) Southern Regional Science Association 2010.
} 


\section{CONCLUSION}

This paper uses an urban economic model to examine the effects of big box retailers on local retail profits, land values, and household utility. Even though our model abstracts away from commuting costs, we find that the big box retailer charges a lower price than small local retailers. The big box price discount is increasing in the size of its marginal cost advantage over downtown retailers. The entry of the big box reduces local retail prices and profits because the big box takes away market share from local businesses. The resulting lower prices and expanded shopping options raise the utility of consumers. The local land market is also affected by the entry of the big box. Land values decrease in the vicinity of the CBD, but increase in the vicinity of the big box.

Household utility is increasing in the distance between the big box and the CBD because of reduced competition for land between the retail locations. The profits of the big box are also increasing in its distance to the CBD because output price does not change, but land rent decreases. It follows that the Pareto optimal location for the big box is bounded away from the CBD. The lower bounds desired by households and the big box coincide and are increasing in the number of households but decreasing in the density of available land. Our analysis also sheds light on the tendency of big boxes to vacate existing retail locations. If the land market is imperfectly competitive, land developers have an incentive to offer rent discounts to attract the big box because land values in surrounding areas increase. Local governments also have an incentive to offer subsidies to encourage big box entry. The analysis predicts larger government subsidies in cities with lower land densities and lower local shopping amenities, and for big box developments further from downtown.

The largely positive welfare conclusions reached in this analysis should be tempered by the recognition that critics and commentators have associated negative features and practices with big box retailers that do not have parametric counterparts in our model. Indeed, one possible interpretation of our results is that if big box retailers are simply larger and more efficient distributors of the same-quality goods as small local retailers, do not create any negative environmental externalities, and do not exert monopsony power in local labor markets, then households will benefit from big box development. While we believe this serves as a useful starting point for considering the issues, in a world that incorporates some of the less laudable qualities alleged, it may very well be the case that utility is not always higher even if prices are always lower.

\section{REFERENCES}

Anas, Alex and Ikki Kim. (1996) "General Equilibrium Models of Polycentric Urban Land Use with Endogenous Congestion and Job Agglomeration," Journal of Urban Economics, 40, $232-256$.

Artz, Georgeanne M. and Kenneth E. Stone. (2006) "Analyzing the Impact of Wal-Mart Supercenters on Local Food Store Sale," American Journal of Agricultural Economics, 88, 1296-1303.

Basker, Emek. (2005a) "Selling a Cheaper Mousetrap: Wal-Mart's Effect on Retail Prices," Journal of Urban Economics, 58, 203-229.

(C) Southern Regional Science Association 2010. 
Basker, Emek. (2005b) "Job Creation or Destruction? Labor Market Effects of Wal-Mart Expansion," Review of Economics and Statistics, 87, 174-183.

Berliant, Marcus and Hideo Konishi. (2000) "The Endogenous Formation of a City: Population Agglomeration and Marketplaces in a Location-Specific Production Economy," Regional Science and Urban Economics, 30, 289-324.

Cavailhes, Jean, Carl Gaigne, and Jacques-Francois Thisse. (2004) "Trade Costs versus Urban Costs," CEPR Discussion Papers, CEPR Discussion Paper 4440.

d'Aspremont, Claude, Jean Gabszewicz, and Jacques-Francois Thisse. (1983) "Product Differences and Prices," Economics Letters, 11, 19-23.

DeFao, Janine. (2003) “Oakland Bans Mega-Grocers,” San Francisco Chronicle, October 23.

Dejka, Joe. (2004) “Wal-Mart Opponents Focus on Location,” Omaha World Herald, June 30.

dePalma, Andre, Qin Liu, and Jacques-Francois Thisse. (1994) “Optimal Locations on a Line with Random Utilities," Transportation Science, 28, 63-69.

Dube, Arindrajit, T. William Lester, and Barry Eidlin. (2007) "Firm Entry and Wages: Impact of Wal-Mart Growth on Earnings throughout the Retail Sector," Available at http://ssrn.com/abstract=841684, August.

The Economist. (2006) "Measuring the Wal-Mart Effect," February.

Fujita, Masahisa and Hideaki Ogawa. (1982) "Multiple Equilibria and Structural Transition of Non-Monocentric Urban Configurations," Regional Science and Urban Economics, 12, 161-196.

Fujita, Masahisa and Jacques-Francois Thisse. (2002) Economics of Agglomeration. Cambridge University Press: Cambridge, United Kingdom.

Fujita, Masahisa, Jacques-Francois Thisse, and Yves Zenou. (1997) "On the Endogenous Formation of Secondary Employment Centers in a City," Journal of Urban Economics, $41,337-357$.

Garrison, Jessica and Sara Lin. (2004) "Wal-Mart vs. Inglewood a Warm-Up for L.A. Fight," The Los Angeles Times, April 2.

Hausman, Jerry and Ephraim Leibtag. (2005) "Consumer Benefits from Increased Competition in Shopping Outlets: Measuring the Effect of Wal-Mart," National Bureau of Economic Research Working Paper 11809.

Henderson, Vernon and Arindam Mitra. (1996) "The New Urban Landscape: Developers and Edge Cities," Regional Science and Urban Economics, 26, 613-643.

Hicks, Michael and Kristy Wilburn. (2001) "The Regional Impact of Wal-Mart Entrance: A Panel Study of the Retail Trade Sector in West Virginia," Review of Regional Studies, 31, 305-313.

Irwin, Elena and Jill Clark. (2006) "The Local Costs and Benefits of Wal-Mart," The Ohio State University Department of Agricultural, Environmental, and Development Economics Working Paper.

(C) Southern Regional Science Association 2010. 
Krause, Thomas W. (1999) "Wal-Mart Store to Close, Reopen Across Street," Macon Telegraph, August 7.

Lohr, Steve. (2003) “Is Wal-Mart Good for America?” The New York Times, December 7.

Malkin, Elisabeth. (2004) “Mexican Retailers Unite Against Wal-Mart,” New York Times, July 9.

McMillen, Daniel P. and Stefani C. Smith. (2003) "The Number of Subcenters in Large Urban Areas," Journal of Urban Economics, 53, 321-338.

Munroe, Scott. (2001) "Retail Structural Dynamics and the Forces behind Big-Box Retailing," Annals of Regional Science, 35, 357-373.

Neumark, David, Junfu Zhang, and Stephen Ciccarella. (2005) "The Effects of Wal-Mart on Local Labor Markets," National Bureau of Economic Research Working Paper 11782.

Ohta, Hiroshi, Yan-Shu Lin, and Masa K. Naito. (2005) "Spatial Perfect Competition: A Uniform Delivered Pricing Model," Pacific Economic Review, 10, 407-420.

Ota, Mitsuru and Masahisa Fujita. (1993) "Communication Technologies and Spatial Organization of Multi-Unit Firms in Metropolitan Areas," Regional Science and Urban Economics, 23, 695-729.

Peng, Shin-Kun and Takatoshi Tabuchi. (2007) "Spatial Competition in Variety and Number of Stores," Journal of Economics and Management Strategy, 16, 227-250.

Rhee, Hyok-Joo. (2004) "Environmental Externalities, Median Voters, and the Multicentric City," Journal of Regional Science, 44, 75-94.

Sanchez, Rene. (2004) "Los Angeles to Wal-Mart: Bigger's Not Always Better; City Leaders Among Many in California Worried Over Superstores' Effects on Local Economy,” The Washington Post, February 3.

Smith, Tony E. and Yves Zenou. (1997) "Dual Labor Markets, Urban Employment and Multicentric Cities," Journal of Economic Theory, 76, 185-214.

Sommer, Constance. (1995) "Super K Developers Urge City to Waive \$1.5 Million in Fees," The Los Angeles Times, March 9.

Wassmer, Robert. (2003) "The Influence of Local Fiscal Structure and Growth Control Choices on 'Big-Box' Urban Sprawl in the American West," in Dick Netzer (ed.), The Property Tax, Land Use and Land Use Regulation. Elgar: Northampton, MA.

Welles, Edward. (1993) "When Wal-Mart Comes to Town," Inc. Magazine, 15(7), 76-83.

(C) Southern Regional Science Association 2010. 


\section{APPENDIX}

Derivation of Condition (9): Someone located at $y<0$ will prefer to shop downtown if and only if $u[\ln (u)-1]-u \ln \left(p_{D}\right)+I+t y-R(y)+A>u[\ln (u)-1]-u \ln \left(p_{B}\right)+I-t L+t y-R(y)$, which is equivalent to $(A+t L) / u>\ln \left(p_{D} / p_{B}\right)$. If this condition is not met, then no one to the left of downtown will want to shop downtown, nor will anyone at any other location. Someone located at $y>L$ will prefer to shop at the big box if and only if $u[\ln (u)-1]-u \ln \left(p_{B}\right)+I-t y+t L-R(y)$ $>u[\ln (u)-1]-u \ln \left(p_{D}\right)+I-t y-R(y)+A$, which is equivalent to $\ln \left(p_{D} / p_{B}\right)>(A-t L) / u$. If this condition does not hold, then no one to the right of the big box will want to shop at the big box, nor will anyone else.

Proof of Proposition 1: Let $B_{L}$ and $B_{R}$ denote the city's left and right boundary points, respectively. Since the length of the city is $N / \delta$, we have $B_{R}-B_{L}=N / \delta$. Since the rents $R_{D}\left(B_{L}\right)$ and $R_{B}\left(B_{R}\right)$ at the boundary points must equal the agricultural rent $R_{A}$ and the utility of households living at the two boundary points must be the same, (7) and (8) imply $B_{L}=$ $(u / t) \ln \left(p_{D} / p_{B}\right)-B_{R}+L-(A / t)$. Solving simultaneously for $B_{R}$ and $B_{L}$ yields $B_{R}=(u / 2 t) \ln \left(p_{D} / p_{B}\right)$ $+(L / 2)-(A / 2 t)+(N / 2 \delta)$ and $B_{L}=(u / 2 t) \ln \left(p_{D} / p_{B}\right)+(L / 2)-(A / 2 t)-(N / 2 \delta)$. The downtown shopping zone is then the interval $\left[B_{L}, y^{*}\right]$, which has a household population of $\delta\left[y^{*}-B_{L}\right]=N / 2$ $-(\delta u / t) \ln \left(p_{D} / p_{B}\right)+(\delta A / t)=N_{D}$. Similarly, the big box shopping zone is the interval $\left[y^{*}, B_{R}\right]$, which has a population of $\delta\left[B_{R}-y^{*}\right]=N / 2+(\delta u / t) \ln \left(p_{D} / p_{B}\right)-(\delta A / t)=N_{B}$

QED.

Proof of Proposition 2: Suppose on the contrary that $p_{D} \leq p_{B}$. Then the market-clearing conditions (11) and (12) imply that $F_{D} p_{D}{ }^{2} / c_{D} u \geq(N / 2)+\delta A / t>(N / 2)-\delta A / t \geq F_{B} p_{B}{ }^{2} / c_{B} u$. Thus, $\left(F_{D} / c_{D}\right) p_{D}{ }^{2}>F_{B} p_{B}{ }^{2} / c_{B}$. It now follows that $1 \geq\left(p_{D} / p_{B}\right)^{2}>\left(F_{B} / F_{D}\right)\left(c_{D} / c_{B}\right)>1$, a contradiction. Hence, $p_{D}>p_{B}$. Now assume (13) holds, so that $(\delta A / t)-(\delta u / t) \ln \left(p_{D} / p_{B}\right)>0$. Then (11) and (12) imply $F_{D} p_{D}{ }^{2} / c_{D} u>(N / 2)>F_{B} p_{B}{ }^{2} / c_{B} u$, so that $\left(p_{D} / p_{B}\right)^{2}>\left(F_{B} / F_{D}\right)\left(c_{D} / c_{B}\right)$. Taking square roots of both sides completes the proof.

QED.

The peak of the downtown rent function $R_{D} *(0)$ is higher than the peak of the big box rent function $\boldsymbol{R}_{B}{ }^{*}(L)$ if and only if (13) holds: Substitute $y=0$ into (18) and $y=L$ into (19) to obtain $R_{D}{ }^{*}(0)=R_{A}+(t / 2)[N / \delta-L]+(A / 2)+(u / 2) \ln \left(p_{B}{ }^{*} / p_{D}{ }^{*}\right)$ and $R_{B}{ }^{*}(L)=R_{A}+(t / 2)[N / \delta-L]-$ $(A / 2)-(u / 2) \ln \left(p_{B}{ }^{*} / p_{D}{ }^{*}\right)$. Observe that $R_{D} *(0)>R_{B} *(L)$ if and only if $A>-u \ln \left(p_{B}{ }^{*} / p_{D}{ }^{*}\right)=$ $u \ln \left(p_{D} * / p_{B}{ }^{*}\right)$, which is condition (13).

Derivation of the cutoff location where land values start to increase due to an increase in the distance between the CBD and the big box: Let $R_{B 1} *(y)$ denote the land rent in the big box area with the original location $L_{1}$, and let $R_{B 2} *(y)$ denote the land rent in the big box area with the new location $L_{2}$. Since $L_{1}<y^{\prime}<L_{2}$, we have $R_{B 1}{ }^{*}\left(y^{\prime}\right)=R_{A}+(t / 2)\left[N / \delta-L_{1}\right]-(A / 2)-(u / 2) \ln \left(p_{B}{ }^{*} / p_{D}{ }^{*}\right)$ $-t y^{\prime}+t L_{1}$ and $R_{B 2} *\left(y^{\prime}\right)=R_{A}+(t / 2)\left[N / \delta-L_{2}\right]-(A / 2)-(u / 2) \ln \left(p_{B}{ }^{*} / p_{D}{ }^{*}\right)+t y^{\prime}-t L_{2}$. We now set $R_{B 1} *\left(y^{\prime}\right)=R_{B 2} *\left(y^{\prime}\right)$, because the old and new rent functions intersect each other at the cutoff location, and solve for $y^{\prime}$ to obtain the result.

Derivation of the Government Subsidy (21): We have $V^{*}$ before $=u[\ln (u)-1]-u \ln \left(p^{*}\right)+I-$ $t N / 2 \delta-R_{A}+A$, and $V^{*}{ }_{\text {after }}=u[\ln (u)-1]-(u / 2) \ln \left(p_{D}{ }^{*}\right)-(u / 2) \ln \left(p_{B}{ }^{*}\right)+I-t N / 2 \delta+t L / 2-R_{A}+$ $(A / 2)$. Taking the utility difference before and after yields $V^{*}{ }_{\text {after }}-V^{*}{ }_{\text {before }}=u \ln \left(p^{*}\right)-$ 
$(u / 2) \ln \left(p_{D}^{*}\right)-(u / 2) \ln \left(p_{B}^{*}\right)+t L / 2-A / 2=(u / 2) \ln \left(p^{* 2}\right)-(u / 2) \ln \left(p_{D}^{*}\right)-(u / 2) \ln \left(p_{B}^{*}\right)+t L / 2-A / 2$, which is $(21)$.

Comparative Static results for the effects of model parameters on the government subsidy: By differentiating the market-clearing condition for the output price in the absence of a big box, $p^{*^{2}}$ $=N c_{D} u / F_{D}$, we obtain the following derivatives: $\mathrm{d} p^{* 2} / \mathrm{d} N=c_{D} u / F_{D}, \mathrm{~d} p^{*^{2}} / \mathrm{d} t=0, \mathrm{~d} p^{*^{2}} / \mathrm{d} A=0$, $\mathrm{d} p^{* 2} / \mathrm{d} \delta=0$, and $\mathrm{d} p^{* 2} / \mathrm{d} L=0$. By differentiating the market-clearing conditions (11) and (12) for the equilibrium prices in the presence of a big box and solving the conditions simultaneously, we obtain the following derivatives:

$$
\begin{aligned}
& \mathrm{d} p_{D} * / \mathrm{d} N=(1 / \Lambda)\left[\left(F_{B} p_{B} / c_{B} u\right)+\left(\delta u / t p_{B}\right)\right], \\
& \mathrm{d} p_{D} * / \mathrm{d} t=-2(1 / \Lambda)\left(\delta / t^{2}\right) A^{\prime}\left[F_{B} p_{B} / c_{B} u\right], \\
& \mathrm{d} p_{D} * / \mathrm{d} A=2(1 / \Lambda)(\delta / t)\left[F_{B} p_{B} / c_{B} u\right], \\
& \mathrm{d} p_{D}^{*} / \mathrm{d} \delta=2(1 / \Lambda)(1 / t) A^{\prime}\left[F_{B} p_{B} / c_{B} u\right], \text { and } \\
& \mathrm{d} p_{D}^{*} / \mathrm{d} L=0, \\
& \text { where } \Lambda=4 F_{D} p_{D} F_{B} p_{B} / c_{D} c_{B} u^{2}+2 \delta F_{B} p_{B} / t c_{B} p_{D}+2 \delta F_{D} p_{D} / t c_{D} p_{B}>0 \text { and } \mathrm{A}^{\prime}=A-u \ln \left(p_{D} / p_{B}\right) . \\
& \mathrm{d} p_{B}^{*} \mathrm{~d} N=(1 / \Lambda)\left[\left(F_{D} p_{D} / c_{D} u\right)+\left(\delta u / t p_{D}\right)\right], \\
& \mathrm{d} p_{B}^{*} / \mathrm{d} t=2(1 / \Lambda)\left(\delta / t^{2}\right) A^{\prime}\left[F_{D} p_{D} / c_{D} u\right], \\
& \mathrm{d} p_{B}^{*} / \mathrm{d} A=-2(1 / \Lambda)(\delta / t)\left[F_{D} p_{D} / c_{D} u\right], \\
& \mathrm{d} p_{B}^{*} / \mathrm{d} \delta=-2(1 / \Lambda)(1 / t) A^{\prime}\left[F_{D} p_{D} / c_{D} u\right], \text { and } \\
& \mathrm{d} p_{B}^{*} / \mathrm{d} L=0 .
\end{aligned}
$$

Taking the derivative of $\Delta V^{*} \equiv\left(V^{*}{ }_{\text {after }}-V^{*}{ }_{\text {before }}\right)$ with respect to each parameter, we find that $\mathrm{d} \Delta V^{*} / \mathrm{d} N$ and $\mathrm{d} \Delta V^{*} / \mathrm{d} t$ could be either positive or negative. Because all prices increase with $N$, the overall effect of $N$ is uncertain. Likewise, since the travel cost savings increase with an increase in $t$, but at the same time the big box price rises more than the downtown price falls, the effect of $t$ on the utility difference is uncertain. We also find that $\mathrm{d} \Delta V^{*} / \mathrm{d} A$ is negative while $\mathrm{d} \Delta V^{*} / \mathrm{d} \delta$ is positive. An increase in the amenity reduces the consumption value associated with big box entry, which, together with an increase in the downtown price, outweighs the decrease in the big box price. An increase in the density of land (and the resulting drop in population density) decreases the big box price more than it increases the downtown price, so the utility gain from big box entry increases. Finally, $\mathrm{d} \Delta V^{*} / \mathrm{d} L>0$ because an increase in big box location reduces the pressure on land values that results from big box entry, increasing the utility gain.

(C) Southern Regional Science Association 2010. 